https://helda.helsinki.fi

Long-term CPAP treatment improves asthma control in patients with asthma and obstructive sleep apnoea

Kauppi, Paula

2016-12

Kauppi , P , Bachour , P , Maasilta , P \& Bachour , A 2016 , ' Long-term CPAP treatment improves asthma control in patients with asthma and obstructive sleep apnoea ' , Sleep and Breathing , vol. 20 , no. 4 , pp. 1217-1224 . https://doi.org/10.1007/s11325-016-1340-1

http://hdl.handle.net/10138/230306

https://doi.org/10.1007/s11325-016-1340-1

publishedVersion

Downloaded from Helda, University of Helsinki institutional repository.

This is an electronic reprint of the original article.

This reprint may differ from the original in pagination and typographic detail.

Please cite the original version. 


\title{
Long-term CPAP treatment improves asthma control in patients with asthma and obstructive sleep apnoea
}

\author{
Paula Kauppi $^{1} \cdot$ Patrick Bachour $^{2} \cdot$ Paula Maasilta $^{2} \cdot$ Adel Bachour $^{2}$
}

Received: 14 October 2015 /Revised: 5 March 2016 / Accepted: 28 March 2016 / Published online: 7 April 2016

(C) Springer-Verlag Berlin Heidelberg 2016

\begin{abstract}
Purpose Both asthma and obstructive sleep apnoea cause sleep disturbance, daytime sleepiness and diminished quality of life. Continuous positive airway pressure (CPAP) is efficient in reducing symptoms related to sleep apnoea. Here we report the impact of long-term use of CPAP on asthma symptoms.

Methods A survey questionnaire was distributed to all of our obstructive sleep apnoea patients with CPAP therapy in 2013. We used the Finnish version of the Asthma Control Test ${ }^{\mathrm{TM}}$ (ACT) and a visual analogue scale $(0=$ no symptoms, $100=$ severe asthma symptoms). Asthma was defined as self-reported physician-diagnosed disease and a special reimbursement for asthma medication by the Social Insurance Institution.

Results We sent 2577 questionnaires and received 1586 answers (61\%). One hundred ninety-seven patients were asthmatics with a prevalence of asthma among CPAP users of $13 \%$. We studied 152 patients (58 females) whose CPAP therapy was initiated after starting asthma medication. Their mean (SD) age was 62 (10) years, duration of CPAP 5.7 (4.7) years and their CPAP daily use was $6.3(2.4) \mathrm{h}$. Self-reported asthma severity decreased significantly from 48.3 (29.6) to 33.1 (27.4) $(p<0.001)$, and ACT score increased significantly from $15.35(5.3)$ to 19.8 (4.6) $(p<0.001)$ without a significant change in the body mass index (BMI). The
\end{abstract}

Paula Kauppi

paula.kauppi@hus.fi

1 Inflammation Centre, Skin and Allergy Hospital, University of Helsinki and Helsinki University Hospital, Meilahdentie 2, P.O. Box 160, FI-00029 HUS Helsinki, Finland

2 Heart and Lung Centre, University of Helsinki and Helsinki University Hospital, Sleep Unit, P.O. Box 160, 00029 Helsinki, Finland percentage of patients using rescue medication daily reduced from 36 to $8 \%$ with CPAP $(P<0.001)$.

Conclusions We noticed a significant decrease in asthma symptoms with long-term use of CPAP in patients with both asthma and obstructive sleep apnoea.

Keywords Asthma $\cdot$ Obstructive sleep apnoea $\cdot$ CPAP

\section{Introduction}

Symptoms of obstructive sleep apnoea (OSA), such as waking up at night with breathing difficulties, snoring and witnessed apnoeas, are common in patients with asthma [1-5]. However, the exact prevalence of OSA in asthmatic patients is not known but the incidence of OSA has been reported to be approximately 2.5 times greater in asthma patients than those without asthma $[5,6]$.

It has been suggested that OSA is an independent risk factor for asthma exacerbation [7], and it has been recommended that physicians evaluate symptoms that suggest OSA and consider differential diagnostics, especially in unstable, poorly controlled asthmatic patients, particularly those who are overweight or obese [8].

The first-line therapy for moderate to severe OSA is continuous positive airway pressure [CPAP], which is considered the most effective therapy to suppress sleep apnoea-related symptoms. Clinical improvement of symptoms after CPAP treatment is directly related to a major reduction in respiratory events and their related consequences during sleep. Specifically, CPAP eliminates or reduces the chronic intermittent hypoxia and sleep fragmentation observed during apnoeic events [9].

In asthmatics with concomitant OSA, CPAP has been shown in a prospective clinical study to have a positive impact on asthma outcome such as improvement in daytime and 
night-time asthma symptoms, reductions in nocturnal bronchodilator use and marked improvement in mean peak expiratory flow rates [6]. The aforementioned study was prospective but short and included a limited number of patients.

Although the number of studies on asthma, asthma and respiratory symptoms and OSA has been increasing, the consequences of CPAP therapy on asthma is not fully understood. The purpose of this study was to evaluate the prevalence of current asthma among CPAP users and describe the effect of long-term CPAP use on asthma symptoms.

\section{Material and methods}

This was a one-centre retrospective cross-sectional questionnaire study on respiratory symptoms and patient's perspective of CPAP therapy on respiratory symptoms in patients with concomitant asthma and OSA. All the patients with diagnosed obstructive sleep apnoea (OSA) $(N=2577)$ and current CPAP therapy of more than 3 months duration in the sleep unit in the Helsinki University Central Hospital were sent a questionnaire in June-July 2013 (diagnosed OSA, current CPAP therapy and self-reported physician diagnosed asthma formed the inclusion criteria) (Fig. 1). The exclusion criteria were asthma diagnosed after starting CPAP therapy, use of CPAP for less than 3 months and OSA without current CPAP therapy.

\section{Asthma}

Asthma was assessed as a self-reported physician-diagnosed disease. In Finland, asthma is diagnosed according to the international guidelines [10]. The criteria for reversible airway obstruction are either a bronchodilator response in spirometry ( $\geq 12 \%$ and $\geq 200 \mathrm{ml}$ ) or moderate to severe bronchial

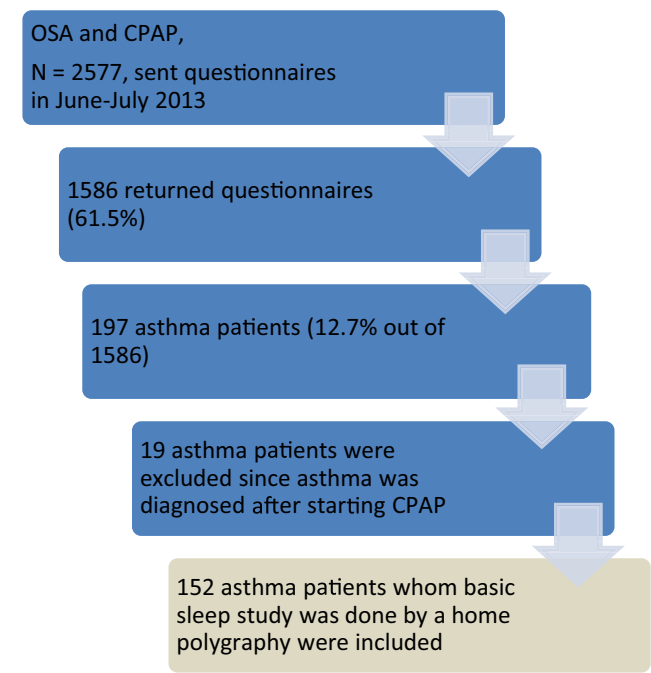

Fig. 1 Flowchart of patient recruitment for sleep apnoea and asthma patients hyperreactivity or a bronchodilator response in peak expiratory flow (PEF) recording ( $\geq 15 \%$ ), a diurnal variation in PEF $(\geq 20 \%)$ or a FEV1/PEF decrease of $\geq 15 \%$ in an exercise test $[11,12]$.

Asthma severity was assessed by a visual analogue scale (VAS) from 0 (no symptoms) to 100 (severe asthma symptoms). In addition, the patients fulfilled the Asthma Control Test ${ }^{\circledR}$ (ACT) concerning their symptoms (score between 5 and $\leq 19$ uncontrolled asthma, 20-24 well-controlled asthma, and score $=25$ totally controlled asthma). Patients reported their asthma symptoms retrospectively both before CPAP treatment and during the last 4 weeks using both ACT and VAS $[13,14]$. ACT questions included use of asthma medication (During the past 4 weeks, how often have you used rescue inhaler or nebulizer medication?). The use of asthma medication was reported before of CPAP treatment and during the last 4 weeks. Asthma patients whose diagnosis was accomplished after starting CPAP therapy were excluded from the analyses.

Smoking status was assessed by the questionnaire. From the patient's file, we obtained values for body mass index and data concerning the use of CPAP and the chronology of asthma. We also analysed changes in body mass index (BMI) using the information on weight and height in the medical records at the time of starting CPAP therapy and at the time of the questionnaire study.

\section{Obstructive sleep apnoea}

The baseline sleep studies were mainly performed with the help of home polygraphy. In few cases, the diagnosis of OSA was done with the help of an in-lab polysomnography (PSG) or a home PSG. To avoid confusion related to the differences in OSA diagnostic method, we included in this study only patients with a home polygraphy. We offered CPAP therapy to patients with a respiratory event index (REI) $>15 / \mathrm{h}$ during a sleep study (out-of-centre sleep test) and to patients with REI 5-14 and symptoms related to OSA [15]. The definition for apnoea was absence of nasal or buccal flow $>10 \mathrm{~s}$. The definition for hypopnoea was a decrease of nasal flow of at least $50 \%$ for at least $10 \mathrm{~s}$ or a decrease of saturation of at least $3 \%$ [16].

CPAP therapy was initiated mainly at home with an automatic PAP device (ResMed, Sydney, Australia), and titration was controlled by oximetry. The pressure was set to start automatically, from $4 \mathrm{cmH} 2 \mathrm{O}$ up to maximum of $20 \mathrm{cmH} 2 \mathrm{O}$. The treatment effect was controlled by oximetry, and normalized results were considered if mean $\mathrm{SPO}_{2}$ values were at least $95 \%$ and ODI4 was less than five per hour [17]. The effect of CPAP therapy on OSA was controlled at 1 week, 3 months and then yearly as previously described [17]. For this study, we only used those who had had CPAP therapy for more than 
3 months. Data were obtained from the memory of the CPAP device at each control visit.

The Helsinki University Central Hospital gave ethics permission (number $\S 192 / 2013$, date 25.5.2013) to organize the study, and the informed consent forms were included in the questionnaires.

\section{Statistical analysis}

Shapiro-Wilk's test $(p>0.05)$ and a visual inspection of their histograms, normal Q-Q plots and box plots showed that the exam scores were approximately normally distributed for the asthma control test score at baseline for both men and women, with a skewness of $-0.287(\mathrm{SE}=0.274)$ and a kurtosis of $-0.960(\mathrm{SE}=0.541)$ for men and a skewness of 0.366 $(\mathrm{SE}=0.365)$ and a kurtosis of $-0.421(\mathrm{SE}=0.717)$ for women.

The ANOVA method was used to compare differences in ACT scores [13]. We used Student's $t$ test for continuous variables with normal distribution and the chi-square tests for categorical variables. If the assumption, in the chi-square test, was violated, we used Fisher's exact test. A $p$ value $<0.05$ was considered statistically significant.

The ACT scores before and after CPAP therapy were first analysed in the total study population and then in the subgroup of asthma patients. We divided patients according to the clinically significant modification in their ACT score into two groups: $\triangle \mathrm{ACT} \geq 3$ group and $\triangle \mathrm{ACT}<3$ group [18].

A multivariate regression analysis was used to define factors that may predict modifications in asthma symptoms measured by the ACT. We run multivariate linear regressions for $\triangle \mathrm{ACT}$ using ACT baseline, CPAP daily use, age, gender, CPAP therapy duration, change in BMI, current smoking, chronic rhinitis, REI baseline, REI CPAP, BMI baseline and the baseline sleep study PSG or polygraphy.

IBM SPSS Statistics software (version 22.0.0.1) (IBM Corporate, New York, USA) was used to compute differences in demographic, clinical and measured variables.

\section{Results}

We received altogether 1586 answers $(61.5 \%)$. The responders (those who returned the questionnaire) were older than the nonresponders (those who did not return the questionnaire), 60 (SD $13)$ vs. $58(12)$ years, respectively $(p<0.001)$. Of the responders, $27 \%$ were women and 45 patients had discontinued using CPAP therapy by the time of questioning. A total of 1530 patients had OSA and a current CPAP treatment (Fig. 1). Of these, 178 had a self-reported physician-diagnosed asthma with special reimbursement for asthma medication in whom asthma diagnosis had been done prior to CPAP therapy. We included 152 patients whose basic sleep study was done by a home polygraph. The mean age of the patients with both asthma and OSA was 62 years (10 years), and $38 \%$ of the patients were women. All the patients had used CPAP therapy a mean of 5.9 years ( 4.8 ) for $6.0 \mathrm{~h} /$ day $(2.5)$, while the respective numbers for both asthma and OSA patients were 5.7 years (4.7) and $6.3 \mathrm{~h} /$ day (2.4) ( $p$ value ns). Minimum of the CPAP use was $0 \mathrm{~h}$ and maximum $10.2 \mathrm{~h} /$ day, median $6.90 \mathrm{~h}$ and percentiles of CPAP use were 5.5 (25th percentile), 6.90 (50th percentile) and 8.0 (75th percentile) in patients with asthma and OSA. CPAP treatment was effective in reducing the apnoea and hypopnoea index from 41.2 to $3.5 / \mathrm{h}$.

We excluded 26 patients as their baseline sleep studies were performed with the help of an in-lab polysomnography (PSG) or home PSG. We found no significant differences between PSG and home polygraph groups regarding their age $[F(2, N=178)=0.15, p=0.99]$, gender $\left[\chi^{2}(2\right.$, $N=178)=2.83, p=0.24]$, CPAP daily use $[F(2$, $N=178)=0.25, p=0.78]$, scores of ACT baseline $[F(2$, $N=178)=0.39, p=0.68]$ or ACT with CPAP $[F(2$, $N=178)=0.10, p=0.91]$.

The severity of asthma symptoms measured by the VAS score decreased from 50.8 (SD 30.7) at baseline before CPAP treatment to 33.6 (25.9) with CPAP in women $[t(39)=4.007, p=0.000])$ and in men from $46.8(29.1)$ to $32.9(28.4)[t(69)=6.483, p=0.000]$. In both women and men, it also decreased significantly from 48.3 (29.6) to $33.1(27.4)[t(109)=7.311, p=0.000]$ (Fig. 2). We found the same trend concerning the self-reported asthma severity expressed by the ACT score. It increased significantly from the baseline at $15.3(5.3)$ to 19.8 (4.2) with CPAP in women $[t(33)=-6.677, p=0.000]$ (Fig. 3) and in men from 17.2 (5.6) to 19.1 (4.9) $[t(67)=-4.373, p=0.000]$, respectively. Moreover, we found a significant correlation between the values of the ACT at baseline and those of the asthma severity at baseline $[r(102)=-0.721, p=0.000]$.

The mean baseline BMI was $37.2(8.7) \mathrm{kg} / \mathrm{m}^{2}$ in women and $33.8(6.0) \mathrm{kg} / \mathrm{m}^{2}$ in men. There was no statistically significant change in the BMI during the time course of CPAP therapy, neither in women nor in men $[t(145)=-0.277$, $p=0.782]$.

The percentage of patients reporting no night-time symptoms was $28 \%$ at baseline and increased significantly [ $\chi^{2}(1$, $N=103)=19.232, p=0.000](p<0.001)$ with CPAP to $55 \%$. Moreover, we noticed a similar amelioration concerning the percentage of patients using rescue medication daily, with a significant reduction from 36 to $8 \%$ with CPAP $(p<0.001)$.

As a value of 3 in the ACT score means a clinically significant change [18], we divided our patients into one group with an ACT change of three or more $(\triangle \mathrm{ACT} \geq 3)$ and another group with an ACT change of less than three $(\triangle \mathrm{ACT}<3)$. We did not find a statistically significant association related to age, daily CPAP use, duration of CPAP therapy, severity of sleep apnoea, values of residual REI or values of BMI at baseline between these two groups. Moreover, the presence 


\section{Severity of asthma at baseline and with CPAP measured by a visual analogue scale}

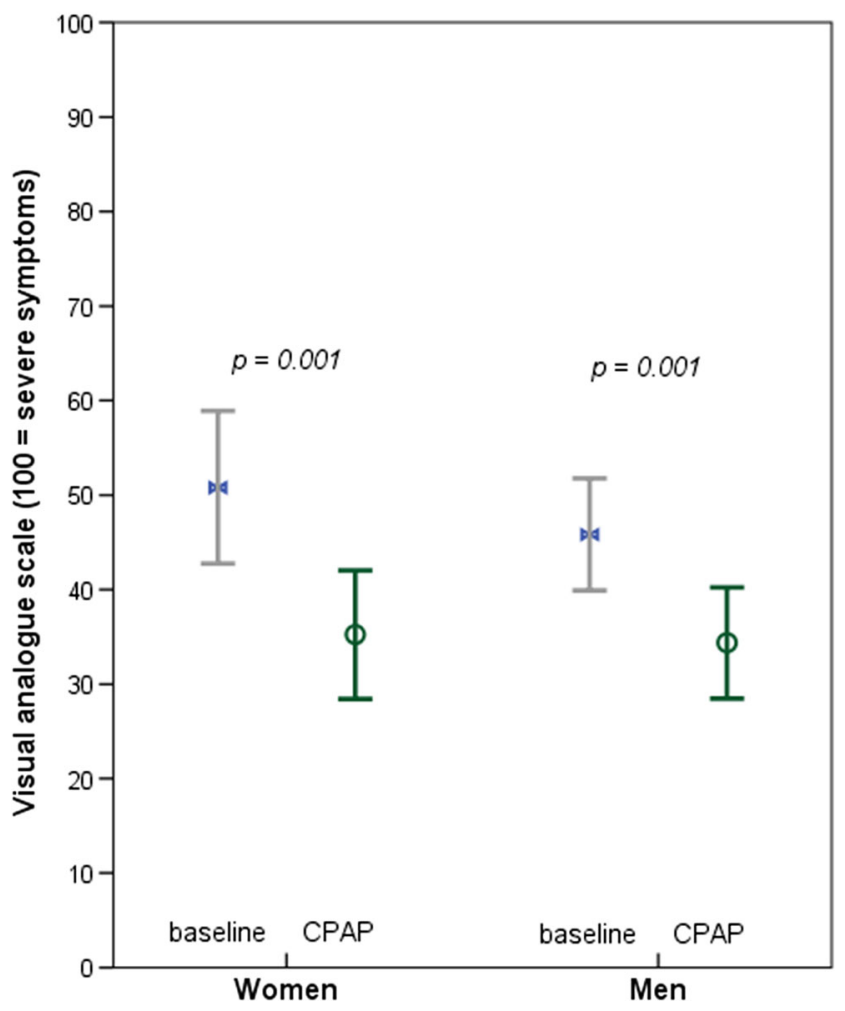

Fig. 2 Self-reported asthma severity on a visual analogue scale (0$100 \mathrm{~mm}$ ) before and during CPAP treatment for OSA

of current smoking, COPD or chronic rhinitis did not differ significantly between the $\triangle \mathrm{ACT} \geq 3$ and $\triangle \mathrm{ACT}<3$ groups (Table 1). Interestingly, women were found significantly more often $(49 \%)$ in the $\triangle \mathrm{ACT} \geq 3$ group compared to the $\triangle \mathrm{ACT}<3$ group $(18 \%)\left[\chi^{2}(1, N=102)=11.294, p=0.001\right]$. The same tendency was noticed in patients with a lower ACT score at baseline $[t(100)=-6.222, p=0.000]$ and in patients with a higher VAS asthma severity score $[t(99)=3.095, p=0.003]$. The absolute value of the BMI at baseline was not associated with the change in the ACT with CPAP $[t(97)=1.063$, $p=0.290]$. Nevertheless, a slight decrease in weight with CPAP (mean of $-1.6 \mathrm{~kg}$ ) was associated with a significant increase in the ACT with CPAP [ $t(97)=-2.740, p=0.007]$.

We performed a multivariate regression analysis to define factors that may predict asthma symptom change measured by the ACT. Table 2 shows age, duration of CPAP therapy, daily CPAP use, change in bodyweight, smoking status, chronic rhinitis, severity of OSA measured by REI, or the efficacy of CPAP on AHI values or the type of the baseline sleep study (polysomnography or a polygraphy) did not show a significant relation to the ACT modification.

Meanwhile, the patient's gender (female), values of BMI at baseline and especially values of ACT at baseline were significant factors in predicting ACT modifications. The regression analysis showed that values of ACT at baseline could significantly predict

\section{Severity of asthma at baseline and with CPAP measured by the Asthma Control Test (ACT)}

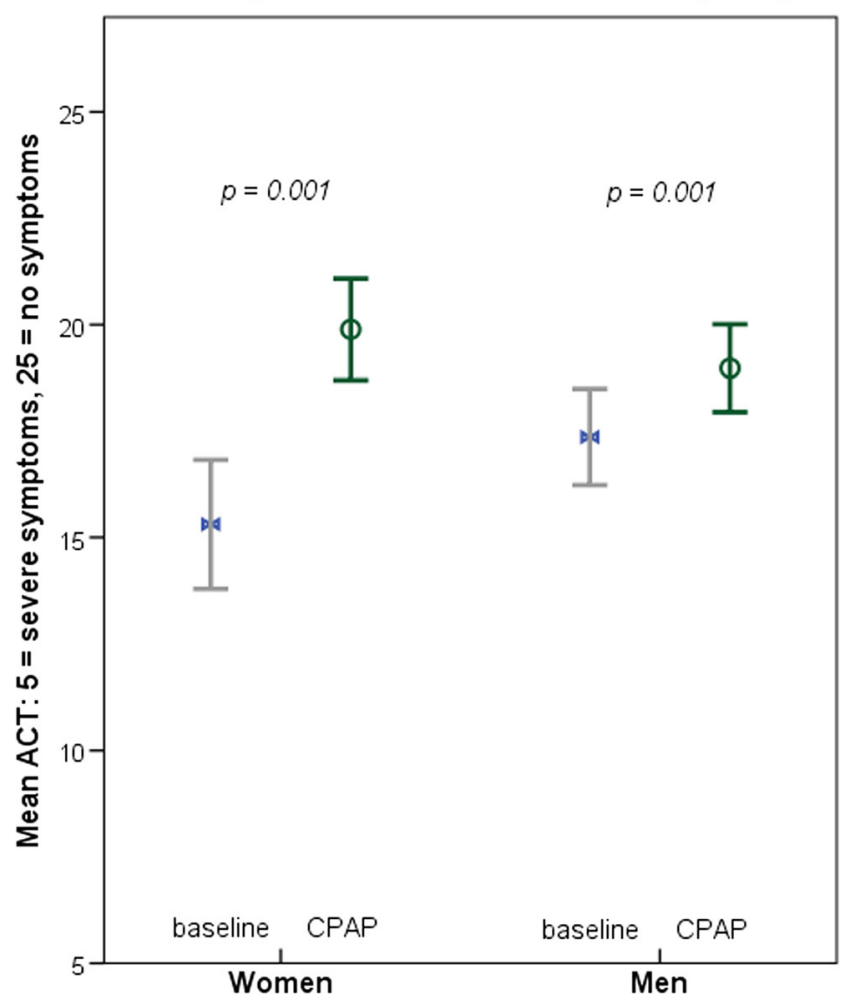

Fig. 3 Asthma control test score results before and during CPAP treatment

$35 \%$ of the ACT modification with long-term CPAP $[p=0.000$, $\left.R^{2}=0.346\right]$. The regression equation was $\hat{\mathrm{Y}} \Delta \mathrm{ACT}=11.220+$ $(-0.502)$ ACT baseline.

\section{Discussion}

We found a prevalence of self-reported asthma of $13 \%$ among long-term CPA users. In this population, long-term CPAP use reduced asthma symptoms measured both by a VAS and ACT significantly. Self-reported asthma severity decreased from 47.6 to 31.6 using the VAS scale during the CPAP treatment. Likewise, the self-reported ACT score increased from 16.5 to 19.3 during the CPAP treatment $(p<0.001)$, showing better asthma control during the CPAP treatment, whereas the BMI of the patients stayed unchanged.

This is the first study showing the long-term effect of CPAP on asthma symptoms in a large patient population. Further, the asthma diagnosis was based on both symptoms, airway reversibility shown in lung function measurements, as well as a response to asthma medication. On the other hand, the effect of CPAP treatment on bronchial hyperreactivity conflicts with reports of either a lack of effect on bronchial hyperreactivity [19] or even a negative effect [20]. In the latter study, bronchial 
Table 1 Comparison of clinical characteristics, asthma severity, OSA severity and CPAP use in the group with $\triangle \mathrm{ACT} \geq 3$ vs. the group with $\triangle \mathrm{ACT}<3$

\begin{tabular}{|c|c|c|c|c|c|c|c|}
\hline & \multicolumn{2}{|c|}{$\geq 3$} & \multicolumn{2}{|c|}{$<3$} & \multirow[b]{2}{*}{$t$} & \multirow[b]{2}{*}{$d f$} & \multirow[b]{2}{*}{$p$ value } \\
\hline & Mean & $\mathrm{SD}$ & Mean & SD & & & \\
\hline Age, years & 63.2 & 8.3 & 63.1 & 10.2 & 0.085 & 100 & 0.932 \\
\hline CPAP daily use (hours) & 7.1 & 1.5 & 6.7 & 1.6 & 1.226 & 100 & 0.223 \\
\hline CPAP since (days) & 2153 & 1682 & 2123 & 1692 & 0.089 & 100 & 0.929 \\
\hline REI baseline & 42.0 & 26.0 & 40.2 & 25.7 & 0.338 & 93 & 0.736 \\
\hline REI residual & 3.4 & 3.3 & 2.8 & 2.3 & 1.022 & 92 & 0.310 \\
\hline BMI baseline $\left(\mathrm{kg} / \mathrm{m}^{2}\right)$ & 35.1 & 7.7 & 33.7 & 5.6 & 1.063 & 97 & 0.290 \\
\hline Bodyweight change (CPAP - baseline, kg) & -1.6 & 11.0 & 3.5 & 6.8 & -2.740 & 97 & 0.007 \\
\hline ACT baseline & 13.6 & 4.0 & 19.5 & 5.4 & -6.222 & 100 & 0.000 \\
\hline \multirow[t]{2}{*}{ Asthma severity VAS baseline } & 56 & 27 & 39 & 28 & 3.095 & 99 & 0.003 \\
\hline & $n(\%)$ & & $n(\%)$ & & $(\chi 2)$ & $d f$ & $p$ value \\
\hline Women & $25(49)$ & & $9(18)$ & & 11.294 & 1 & 0.001 \\
\hline Current smoker & $7(14)$ & & $5(10)$ & & 0.378 & 1 & 0.539 \\
\hline COPD & $13(26)$ & & $14(28)$ & & 0.050 & 1 & 0.822 \\
\hline Chronic rhinitis & $16(31)$ & & $21(41)$ & & 1.060 & 1 & 0.303 \\
\hline
\end{tabular}

ACT means asthma control test: 5 = severe symptoms, 25 = no symptoms; asthma severity measured by a visual analogue scale, $0=$ no symptoms, $100=$ severe asthma symptoms

$R E I$ respiratory event index hyperreactivity was increased in 57 OSA patients after 3 weeks of CPAP therapy compared to the baseline.

Previous studies on asthma and OSA have been smaller, including 9-50 patients, and have had a shorter duration of CPAP treatment ranging from 2 weeks to 6 months [19, 21-23], whereas we had altogether 178 patients with self-reported physiciandiagnosed asthma and current CPAP treatment for OSA, whose CPAP therapy had continued for a mean of 5.5 years.
In the earlier studies, night-time asthma symptoms and nocturnal bronchodilator use were reported to be reduced by CPAP treatment in asthma patients [21, 22]. Further, daytime asthma symptoms have been reported to decrease and asthma-specific quality of life to improve due to CPAP therapy [19, 21, 23]. Our results were in accordance with the previous study results although our study was a retrospective questionnaire study without objective pulmonary function test measurements before and
Table 2 Predictors of amelioration of asthma symptoms with the long-term CPAP therapy with a multivariate regression analysis

\begin{tabular}{|c|c|c|c|c|c|}
\hline \multirow[t]{2}{*}{ Model } & \multicolumn{2}{|c|}{$\begin{array}{l}\text { Unstandardized } \\
\text { coefficients }\end{array}$} & \multirow{2}{*}{$\begin{array}{l}\text { Standardized } \\
\text { coefficients } \\
\text { Beta }\end{array}$} & \multirow[t]{2}{*}{$t$} & \multirow[t]{2}{*}{$\begin{array}{l}p \\
\text { value }\end{array}$} \\
\hline & $B$ & $\begin{array}{l}\text { Std. } \\
\text { error }\end{array}$ & & & \\
\hline (Constant) & 22.926 & 5.505 & & 4.164 & .000 \\
\hline Asthma control test, ACT (baseline) & -0.474 & 0.078 & -0.543 & -6.091 & .000 \\
\hline CPAP daily use & 0.253 & 0.272 & 0.081 & 0.932 & .354 \\
\hline Age & -0.081 & 0.049 & -0.156 & -1.637 & .106 \\
\hline Gender & -2.125 & 0.954 & -0.211 & -2.228 & .029 \\
\hline CPAP treatment duration & 0.000 & 0.000 & -0.048 & -0.537 & .593 \\
\hline $\begin{array}{l}\text { Change in body weight } \\
\text { (baseline - CPAP) }\end{array}$ & -0.086 & 0.049 & -0.173 & -1.760 & .082 \\
\hline Current smoking & 0.224 & 1.330 & 0.015 & 0.168 & .867 \\
\hline Chronic rhinitis & -0.054 & 0.897 & -0.005 & -0.060 & .952 \\
\hline $\begin{array}{l}\text { Respiratory event index, REI } \\
\text { (baseline) }\end{array}$ & 0.016 & 0.019 & 0.087 & 0.864 & .390 \\
\hline REI (CPAP) & 0.194 & 0.152 & 0.115 & 1.278 & .205 \\
\hline Body mass index (baseline) & -0.197 & 0.078 & -0.280 & -2.530 & .013 \\
\hline
\end{tabular}


during CPAP therapy. Both VAS and the ACT test have been used when estimating asthma symptoms and asthma control even though sleep disturbance might be associated to either OSA or asthma or both. Here, the number of patients using rescue medication two to three times per week reduced significantly from 19 to $13 \%$ with CPAP treatment, and those not needing rescue medication significantly increased from 33 to $36 \%(p<0.001)$ which was the level of asthma medication follow-up that was estimated possible when planning the study. In a prospective setting, a number of per oral steroid courses per year and a dose of inhaled corticosteroids should be followed. However, even if the asthma medication would be analysed further, it is according to patients' reports. The actual count of used medication is followed only in clinical trials and elsewhere (both in the medical records and in clinical studies), the information is based on the patient report. Since directly observed treatment is not used in asthma treatment, there is no absolute method for medication treatment adherence. Further, the $13 \%$ prevalence of asthma among CPAP users in here is almost twice the reported prevalence of asthma patients with special reimbursement for medication in Finland (6.6\% in the year 2011) [24].

Neutrophilic inflammation of lower airways demonstrated by sputum samples has been reported in OSA patients without CPAP treatment [25]. Salerno et al. hypothesized that this might be caused by intermittent upper airway obstruction and mechanical mucosal stress. Further, neutrophilic lower airway inflammation would lead to airway obstruction. In the study of Salerno et al., BMI or obesity was not correlated to sputum neutrophilia but OSA was. Obesity and sleep apnoea are more likely to be associated with a neutrophilic asthma phenotype than an allergic and/or eosinophilic asthma phenotype, offering an explanation for the reduced probability of reaching an optimal asthma control level with traditional asthma therapy such as inhaled corticosteroids, long-acting bronchodilators and antileukotrienes [23, 26, 27]. Obesity has been associated with asthma both as a risk factor for asth$\mathrm{ma}$ and as a modifying factor of the disease $[28,29]$. Since this was a questionnaire study we did not have the option of studying sputum samples to differentiate between eosinophilic and neutrophilic asthma phenotypes. However, our results are in agreement with earlier ones [30] in which obese patients did not lose weight after the initiation of CPAP therapy. Further, the improvements in asthma control in our patients were not a result of weight loss.

The positive effect of CPAP on respiratory symptoms was greater in women and in those with poorer ACT and VAS values. Asthma is more common in women, and OSA is more often found in men [26]. Obesity is associated with both OSA and more severe asthma. OSA patients with concomitant asthma have probably more respiratory symptoms than patients with only OSA. These results are suggestive for and additive treatment option to traditional asthma medication in obese asthmatic women and especially in patients with both asthma and OSA.

The benefits of CPAP treatment on asthma symptoms in asthma and OSA patients are multiple. CPAP therapy has been suggested to reduce systemic inflammation associated with OSA. CPAP treatment has been reported to decrease hypoxia and oxidative stress, to decrease neutrophil superoxide dismutase generation and superoxide release, and to lower CRP and vascular endothelial growth factor (VEGF) levels [6]. One of the mechanisms of CPAP therapy that may be effective in asthma is improving the acinar ventilation heterogeneity that has been shown to exist even during inhaled corticosteroid therapy [31]. Decreasing acinar ventilation heterogeneity might simply lead to improved ventilation but also secondarily decrease the local inflammation process. Further, improvements in reflux syndrome might contribute to reducing both any nighttime respiratory symptoms and also specifically nighttime asthma symptoms [6, 32].

In our study, none of the following variables (age, daily CPAP use, duration of CPAP therapy, severity of sleep apnoea, values of residual REI) were associated with an increase in ACT scores of three or more. Nevertheless, a slight decrease in BMI with CPAP was associated with a significant increase in ACT with CPAP, pointing to the role of body weight regulation in the pathogenesis of asthma symptoms. In addition, female gender, ACT baseline and BMI baseline values were predictive for a greater response (measured by ACT) to CPAP therapy.

The study has some limitations as it is a questionnaire study. Moreover, we did not report the effect on pulmonary function test results of CPAP therapy, nor comorbidity, which may influence asthma symptoms. We hypothesize that regular CPAP users are motivated patients, and motivation may also increase compliance to other treatments such as asthma medication. In addition, our reported results concerning asthma severity are both self-reported and retrospective, both of which include a possibility of recall bias. Thus, a prospective follow-up study with a control group should be performed to validate these study results. Those who answered our questionnaire were compliant CPAP users $(6.3 \mathrm{~h} /$ day $)$. The compliance in this study was greater than what we have reported previously $(5.6 \mathrm{~h} \pm 1.5)$ [33], probably because of high prevalence of asthma in this study. It is possible that asthma patients with OSA are more symptomatic and thus also more compliant than average CPAP users. This may have had a positive impact on their answers to asthma symptoms before and during CPAP therapy compared to those with OSA and asthma but no CPAP therapy. Further, our results cannot be generalized to the overall asthma population but only to those with concomitant sleep apnoea syndrome. However, a recent study on patients with severe asthma 
by D'Amato et al. reported improvement in asthma control with CPAP therapy and reduction in PEF variability in patients without OSA [34]. In addition, these analyses and results are limited to the patients with OSA diagnosed with an ambulatory home polygraphy and thus may underestimate the true prevalence or severity of OSA in these patients [35]. Further, no formal in-lab CPAP titration was performed and instead CPAP therapy was initiated at home with an automatic PAP device and titration was controlled by oximetry. In a prospective setting, the use of an in-lab PSG and an in-lab CPAP titration would be more exact methods and thus recommended.

In conclusion, we noticed a statistically and clinically significant improvement in asthma control in patients using CPAP. This reduction in self-reported asthma severity could not be interpreted as a change in BMI. If asthma control is not achieved in obese patients, then the possibility of coexisting OSA should be assessed and CPAP therapy offered.

Acknowledgments $\mathrm{PK}$ and $\mathrm{AB}$ had full access to all of the data and contributed substantially to the study design, data analysis and interpretation and the writing of the manuscript. PB had full access to data and contributed substantially to the data analysis and writing of the manuscript. PM contributed substantially to the study design, data interpretation and the writing of the manuscript.

Compliance with ethical standards All procedures performed in studies involving human participants were in accordance with the ethical standards of the institutional and/or research committee and with the 1964 Helsinki declaration and its later amendments or comparable ethical standards.

Funding The Helsinki University Special Fund provided financial support in the form of research grant funding. The sponsor had no role in the design or conduct of this research.

Conflict of interest All authors certify that they have no affiliations with or involvement in any organization or entity with any financial interest (such as honoraria; educational grants; participation in speakers' bureaus; membership, employment, consultancies, stock ownership, or other equity interest; and expert testimony or patent licensing arrangements) or non-financial interest (such as personal or professional relationships, affiliations, knowledge or beliefs) in the subject matter or materials discussed in this manuscript.

Informed consent Informed consent was obtained from all individual participants included in the study.

\section{References}

1. Auckley D, Moallem M, Shaman Z, Mustafa M (2008) Findings of a Berlin questionnaire survey: comparison between patients seen in an asthma clinic versus internal medicine clinic. Sleep Med 9:494-499

2. Ekici A, Ekici M, Kurtipek E, Keles H, Kara T, Tunckol M, Kocyigit P (2005) Association of asthma-related symptoms with snoring and apnea and effect on health-related quality of life. Chest 128:3358-3363
3. Teodorescu M, Barnet JH, Hagen EW, Palta M, Young TB, Pepppard PE (2015) Association between asthma and risk of developing obstructive sleep apnea. JAMA 313:156-164

4. Teodorescu M, Broytman O, Curran-Everett D, Sorkness RL, Crisafi G, Bleecker ER, Erzurum S, Gaston BM, Wenzel SE, Jarjour NN, National Institutes, National Heart, Lung and Blood Institute Severe Asthma Research Program (SARP) Investigators (2015) Obstructive sleep apnea risk, asthma burden, and lower airway inflammation in adults in the Severe Asthma Research Program (SARP) II. J Allergy Clin Immunol Pract 3:566-75.e1. doi:10.1016/j.jaip.2015.04.002

5. Shen TC, Lin CL, Wei CC, Chen CH, Tu CY, Hsia TC, Shih CM, Hsu WH, Sung FC, Kao CH (2015) Risk of obstructive sleep apnea in adult patients with asthma: a population-based cohort study in Taiwan. PLoS One 10(6):e0128461. doi:10.1371/journal.pone. 0128461

6. Alkhalil M, Schulman ES, Getsy J (2008) Obstructive sleep apnea syndrome and asthma: the role of continuous positive airway pressure treatment. Ann Allergy Asthma Immunol 101:350-357. doi: 10.1016/S1081-1206(10)60309-2

7. Ten Brinke A, Sterk PJ, Masclee AA, Spinhoven P, Schmidt JT, Zwinderman AH, Rabe KF, Bel EH (2005) Risk factors of frequent exacerbations in difficult-to-treat asthma. Eur Respir J 26:812-818

8. Luyster FS, Teodorescu M, Bleecker E, Busse W, Calhoun W, Castro M, Chung KF, Erzurum S, Israel E, Strollo PJ, Wenzel SE (2012) Sleep quality and asthma control and quality of life in nonsevere and severe asthma. Sleep Breath 16:1129-1137. doi:10. 1007/s11325-011-0616-8

9. Hoffstein V, Viner S, Mateika S, Conway J (1992) Treatment of obstructive sleep apnea with nasal continuous positive airway pressure: patient compliance, perception of benefits, and side effects. Am Rev Respir Dis 145:841-845

10. Reddel HK, Taylor DR, Bateman ED, et al. (2009) American Thoracic Society/European Respiratory Society Task Force on asthma control and exacerbations. an official American Thoracic Society/European Respiratory Society Statement: asthma control and exacerbations. Am J Respir Crit Care Med 180:59-99. doi: 10.1164/rccm.200801-060ST

11. Viljanen AA, Halttunen PK, Kreus KE, Viljanen BC (1982) Spirometric studies in non-smoking, healthy adults. Scand J Clin Lab Invest Suppl 159:5-20

12. Miller MR, Hankinson J, Brusasco V, Burgos F, Casaburi R, Coates A, Crapo R, Enright P, van der Grinten CP, Gustafsson P, Jensen R, Johnson DC, MacIntyre N, McKay R, Navajas D, Pedersen OF, Pellegrino R, Viegi G, Wanger J (2005) Standardisation of spirometry. ATS/ERS Task Force. Eur Respir J 26:319-338

13. Schatz M, Sorkness CA, Li JT, Marcus P, Murray JJ, Nathan RA, Kosinski M, Pendergraft TB, Jhingran P (2006) Asthma control test: reliability, validity, and responsiveness in patients not previously followed by asthma specialists. J Allergy Clin Immunol 117:549-556

14. Demoly P, Bousquet PJ, Mesbah K, Bousquet J, Devillier P (2013) Visual analogue scale in patients treated for allergic rhinitis: an observational prospective study in primary care: asthma and rhinitis. Clin Exp Allergy 43:881-888. doi:10.1111/cea.12121

15. American Academy of Sleep Medicine (2014) International classification of sleep disorders, 3rd edn. Darien, Illinois

16. Maasilta P, Bachour A, Teramo K, Polo O, Laitinen LA (2001) Sleep-related disordered breathing during pregnancy in obese women. Chest 120:1448-1454

17. Bachour A, Virkkala JT, Maasilta PK (2007) AutoCPAP initiation at home: optimal trial duration and cost-effectiveness. Sleep Med 8:704-710

18. Schatz M, Kosinski M, Yarlas AS, Hanlon J, Watson ME, Jhingran P (2009) The minimally important difference of the asthma control test. J Allergy Clin Immunol 124:719-723. doi:10.1016/j.jaci.2009.06.053 
19. Lafond C, Series F, Lemiere C (2007) Impact of CPAP on asthmatic patients with obstructive sleep apnea. Eur Respir J 29:307-311

20. Devouassoux G, Levy P, Rossini E, Pin I, Fior-Gozlan M, Henry M, Seigneurin D, Pépin JL (2007) Sleep apnea is associated with bronchial inflammation and continuous positive airway pressure-induced airway hyperresponsiveness. J Allergy Clin Immunol 119:597-603

21. Chan CS, Woolcock AJ, Sullivan CE (1988) Nocturnal asthma: role of snoring and obstructive sleep apnea. Am Rev Respir Dis 137: $1502-1504$

22. Guilleminault C, Quera-Salva MA, Powell N, Riley R, Romaker A, Partinen M, Baldwin R, Nino-Murcia G (1988) Nocturnal asthma, snoring, small pharynx and nasal CPAP. Eur Respir J 1:902-907

23. Ciftci TU, Ciftci B, Guven SF, Kokturk O, Turktas H (2005) Effect of nasal continuous positive airway pressure in uncontrolled nocturnal asthmatic patients with obstructive sleep apnea syndrome. Respir Med 99:529-534

24. Jantunen J, Kauppi P, Linna M, Martikainen J, Mäkelä M, Pelkonen A, Haahtela T (2014) Astman ja allergian kustannukset ovat suuret, mutta laskussa. (the costs of asthma and allergy are large but are decreasing. In Finnish). Finn Med J 9:641-647

25. Salerno FG, Carpagno E, Guido P, Bonsignore MR, Roberti A, Aliani M, Vignola AM, Spanevello A (2004) Airway inflammation in patients affected by obstructive sleep apnea syndrome. Respir Med 98:25-28

26. Wenzel SE (2012) Asthma phenotypes: the evolution from clinical to molecular approaches. Nat Med 18:716-725. doi:10.1038/nm.2678

27. Wood LG, Baines KJ, Fu J, Scott HA, Gibson PG (2012) The neutrophilic inflammatory phenotype is associated with systemic inflammation in asthma. Chest 142:86-93. doi:10.1378/chest.11-1838
28. Schachter LM, Salome CM, Peat JK, Woolcock AJ (2001) Obesity is a risk for asthma and wheeze but not airway hyperresponsiveness. Thorax 56:4-8

29. Holguin F, Bleecker ER, Busse WW, Calhoun WJ, Castro M, Erzurum SC, Fitzpatrick AM, Gaston B, Israel E, Jarjour NN, Moore WC, Peters SP, Yonas M, Teague WG, Wenzel SE (2011) Obesity and asthma: an association modified by age of asthma onset. J Allergy Clin Immunol 127:1486-93. e2. doi:10.1016/j. jaci.2011.03.036

30. Drager LF, Brunoni AR, Jenner R, Lorenzi-Filho G, Benseñor IM, Lotufo PA (2015) Effects of CPAP on body weight in patients with obstructive sleep apnoea: a meta-analysis of randomised trials. Thorax 70:258-264. doi:10.1136/thoraxjnl-2014-205361

31. Hanon S, Schuermans D, Vincken W, Verbanck S (2014) Irreversible acinar airway abnormality in well controlled asthma. Respir Med 108:1601-1607. doi:10.1016/j.rmed.2014.07.019

32. Prasad B, Nyenhuis SM, Weaver TE (2014) Obstructive sleep apnea and asthma: Associations and treatment implications. Sleep Med Rev 18:165-171. doi:10.1016/j.smrv.2013.04.004

33. Bachour A, Vitikainen P, Virkkula P, Maasilta P (2013) CPAP interface: satisfaction and side effects. Sleep Breath 17:667-672

34. D'Amato M, Stanziola AA, de Laurentiis G, Diana R, Russo C, Maniscalco M, D'amato G, Sofia M (2014) Nocturnal continuous positive airway pressure in severe non-apneic asthma. A pilot study. Clin Respir J 8:417-424. doi:10.1111/crj.12088

35. Collop NA, Tracy SL, Kapur V, Mehra R, Kuhlmann D, Fleishman SA, Ojile JM (2011) Obstructive sleep apnea divices for out-of-center (OOC) testing: technology evaluation. J Clin Sleep Med 7:531-548 